\title{
Optimization of Bus Body Frame Structure for Weight Minimizing with Constraint of Natural Frequency using Adaptive Single-Objective Method
}

\author{
Ismoyo Haryanto $^{1,2 *}$, Fuad Arief Raharjo ${ }^{1}$, Ojo Kurdi ${ }^{1,2}$, Gunawan Dwi Haryadi ${ }^{1,2}$, Sigit Puji Santosa ${ }^{2,3}$, \\ Leonardo Gunawan ${ }^{2,3}$ \\ ${ }^{1}$ Department of Mechanical Engineering, Faculty of Engineering, University of Diponegoro, Semarang, Indonesia \\ ${ }^{2}$ National Center for Sustainable Transportation Technology, Indonesia \\ ${ }^{3}$ Faculty of Mechanical and Aerospace Engineering, Institut Teknologi Bandung, Indonesia \\ *Email: ismoyo_h@undip.ac.id
}

\begin{abstract}
The objective of this work is to analyze and optimize a bus frame structure using Finite Element Method in dynamic conditions. The bus body geometry was obtained directly from the three-dimensional Computer-Aided Design files. The optimization was conducted to determine the minimum weight of the bus frame structure without violating the specified natural frequency constraints. The design variable is the thickness of the bus body frame. In present study, Adaptive Single Objective method was chosen as an optimizer method. The results show that the structural weight of the bus frame can be reduced about $8 \%$ without changing its dynamic characteristic.
\end{abstract}

\section{Keywords}

Bus frame structure; Finite element method; Optimization; Minimum-weight; Adaptive single objective

\section{Introduction}

The transport activities are responsible for the consumption of a large percentage of oil reserves worldwide over the last decades. This sector also accounts a big contribution of total greenhouse gas emission. For the most part, this is due to road transport $[1,2]$. Nowadays, the concept of an alternative propulsion is becoming increasingly important as a consequence of climate change and the increasing global resource crisis. Due to the advances in battery technology, greater attention is now directed to the concept of battery-powered electrical propulsion. In addition, electric vehicles are also believed to be an effective solution for reducing greenhouse gas emissions [3].

A bus is used as the most common public transport vehicle in any country. The electrification of a bus as mass transportation fleets will give an important meaning in the country in terms of economic, social, and environmental aspects. It can be stated that the electric bus is a demand in the future. At the other side, the existence of an efficient, sustainable, and environmentally friendly transport system requires several challenges to be addressed to meet many requirements in terms of transport performance, comfort, safety, energy consumption and costs, quality and reliability as well as environmental impact [4]. There is no other choice unless those requirements have to be considered since in the design stage. To reduce production costs and improve energy efficiency, a weight reduction of vehicle body structures is pursued [5]. Therefore, it is a great significance to utilize the numerical optimization procedure in the design of bus structure to obtain the minimum structural weight on the basis of mechanical characters and vibration performance.

The present work deals with the analyzing and optimizing a bus frame using Finite Element Method (FEM) in dynamic conditions. In this study, beam element was extensively used to create the frame structure of bus body because it can not only archive the accurate stiffness but also reduce much computational cost $[6,7]$. The bus body geometry was obtained directly from the three-dimensional Computer-Aided Design (CAD) files. Furthermore, the optimization was conducted using the method of Adaptive Single Objective (ASO) for determining the minimum weight of bus frame without violating the natural frequency constraints. The design variables are the thickness of the bus body frame.

\section{The Bus Frame Model}

The bus body structure comprises of six main components, which are the left and right frame sides, the front and back frame sides, the top and bottom frame sides. The top frame side is sometimes called roof frame 
side. Meanwhile, its bottom side is called floor frame side. Bus frame serves to form the whole bus body and has a very important role that affects the stability and comfort of the bus at the operational condition. The bus frame is also a place to attach other bus components such as bus body, glass, interior, air-conditioner, and passenger seat on the bus.

Figure 1 shows the bus body frame used in this study, with the specifications given in Table 1 . The bus has the capacity of 31 seats. This is a tentative model which was taken from the journal specified in the literature survey. It is assumed that the frame consists of several tabular beams with welded-joint. The bus frame is constructed using 3D sketches and the beams establishing the frame are represented by lines. Those beams are grouped based on the structural member types. The connections of the lines are indicated by nodal which describes the joint of the bus frame. Table 2 shows the properties correspond to the structural steel used in this study. The final FEM model is shown in Figure 1. In total, the model used nodes of 527,715, elements of 266,915, connector of 682 and beam of 365 .

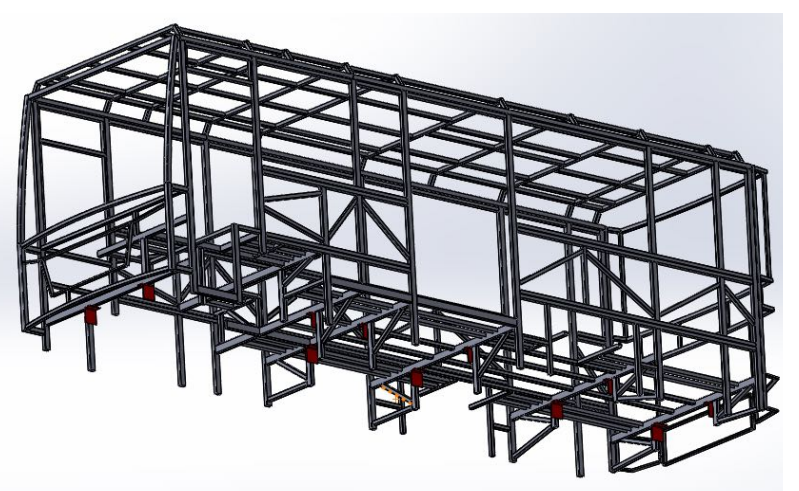

Figure 1 Vibration mode of bus body frame model

Table 1 Natural frequencies of the bus frame

\begin{tabular}{lc}
\hline \multicolumn{2}{c}{ Basic dimensions } \\
\hline Length $(\mathrm{mm})$ & 7,481 \\
Wide $(\mathrm{mm})$ & 2,100 \\
High $(\mathrm{mm})$ & 2,694 \\
Capacity (seats) & 31 \\
\multicolumn{2}{c}{ Frame } \\
\hline Material & Steel \\
Weight $(\mathrm{kg})$ & 840.47 \\
\hline
\end{tabular}

Table 2 Material Properties of Steel

\begin{tabular}{lc}
\hline \multicolumn{1}{c}{ Properties } & Value \\
\hline Density $\left(\mathrm{kg} / \mathrm{m}^{3}\right)$ & 7,700 \\
Poisson ratio & 0.3 \\
Modulus of elasticity $(\mathrm{GPa})$ & 220 \\
\hline
\end{tabular}

\section{Free Modal Analysis}

The main objective of the free modal analysis is to determine natural frequencies and the corresponding vibration modes. For the high-order of vibration mode, the deformation will be small and the frequency has a small effect on the structural dynamic. Thus, in this study, only the first 6 order of natural frequencies and vibration modes are taken into account with removing the rigid modes. Table 3 shows the first 6 order natural frequencies of the bus body frame and the corresponding vibration modes are shown in Figure 2.

The vehicle frequency of a bus is normally about $3 \mathrm{~Hz}$ and the ground excite frequency is about $1-3 \mathrm{~Hz}$ [5]. In the present study, it is found that the lowest frequency of bus body is about $5.49 \mathrm{~Hz}$. It means that the natural frequencies of the bus body can avoid the ground excite frequency and the vehicle frequency, the design requirements of the bus body frame can be fulfilled.

Table 3 Specification of bus body

\begin{tabular}{|c|c|}
\hline \multicolumn{2}{|c|}{ Basic dimensions } \\
\hline Length (mm) & 7,481 \\
\hline Wide (mm) & 2,100 \\
\hline High (mm) & 2,694 \\
\hline Capacity (seats) & 31 \\
\hline \multicolumn{2}{|c|}{ Frame } \\
\hline Material & Steel \\
\hline Weight (kg) & 840.47 \\
\hline
\end{tabular}

\section{Optimization Procedures}

According to the free modal analysis results, it can be shown that the natural frequencies of the bus frame meet the design and usage requirements. However, a weight reduction of vehicle body structures is pursued reducing production costs and improving energy efficiency without violating the vehicle modal requirements. For this purpose, the original body is redesigned by changing the thickness utilizing numerical optimization procedures so that the total weight of the bus structure is minimized.

The problem of optimization can be formulated as:

Minimize:

$$
f=f(\{x\})
$$

Subjected to

$$
\begin{aligned}
& g_{k}(\{x\}) \leq 0, \forall k=1,2, \ldots, K \\
& h_{1}(\{x\}) \leq 0, \forall l=1,2, \ldots, L \\
& \left\{x_{L}\right\} \leq\{x\} \leq\left\{x_{U}\right\}
\end{aligned}
$$

where $x_{L}$ and $x_{U}$ are the upper and lower bound of design variables, respectively. In this study, the 
thickness of tabular beams is treated as a design variable whereas the objective function as the function that will be minimized is the total mass of the structure.

\subsection{Adaptive single-objective}

The method of ASO was utilized in this study. ASO is a mathematical optimization method that combines a Latin Hypercube Sampling (LHS) Design of Experiments, a Kriging response surface, and the Nonlinear Programming by Quadratic Lagrangian (NLPQL) optimization algorithm. It is a gradient-based algorithm based on a response surface which provides a refined, global, and optimized result. This method was chosen due to some benefits, such as: employing automatic intelligent refinement to provide the global optima, reducing the number of design points necessary
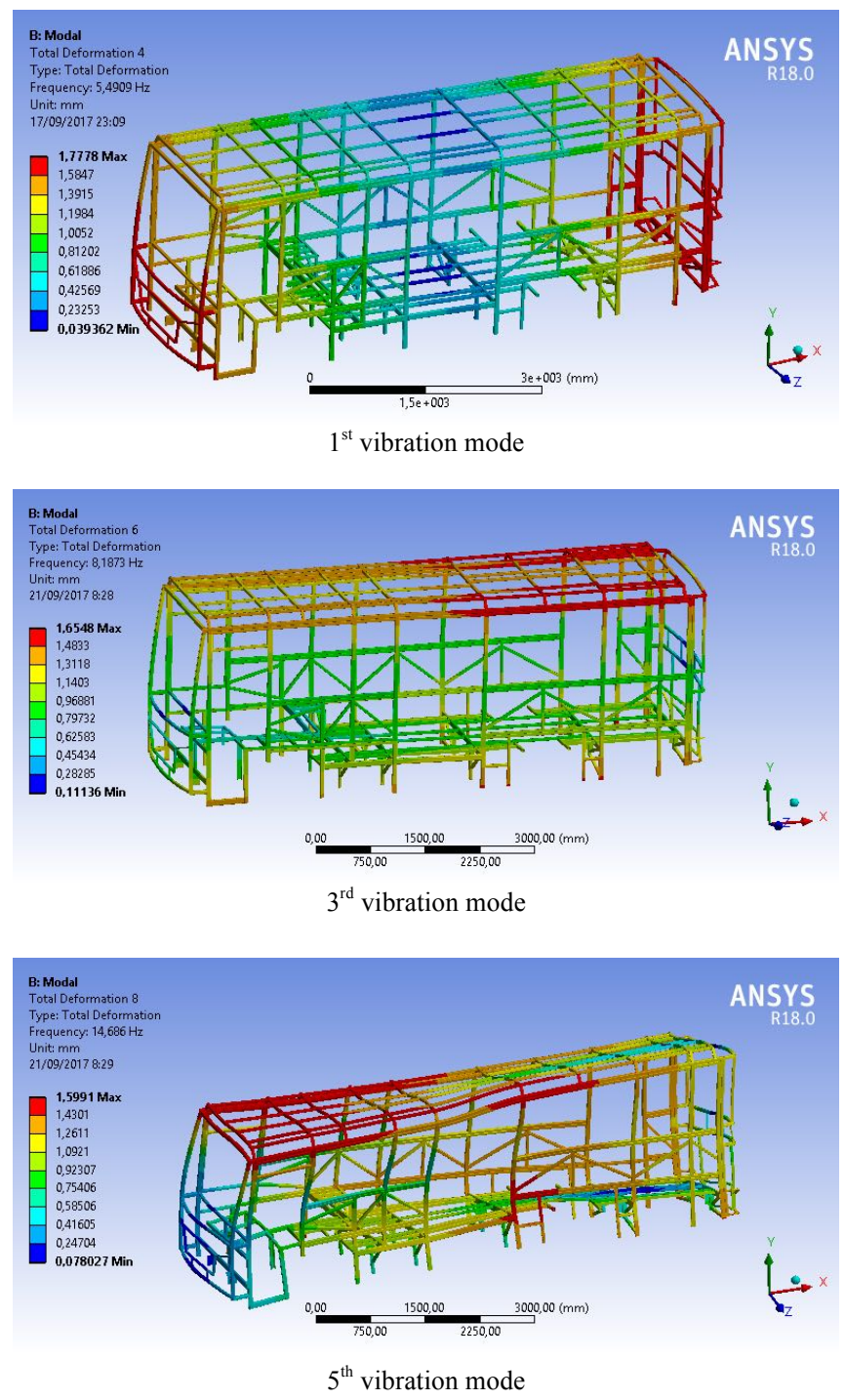

for the optimization, and failed design points are treated as inequality constraints making it fault-tolerant [8].

\subsection{Design variable}

In this paper, the optimization problem was simplified by considering the correlation of the design variables with similar beams constructing the bus body frame. For this purpose, the beams are grouped based on the dimension and the cross-section. There are three main sections of the beam used to form the current body frame structure, i.e.: rectangular, square and U-beam. Figure 3 shows the grouping of beams was performed for the present study (indicated by pink color). The optimization is utilized to reduce the thickness of the tabular beams in each group. So that ten design variables are available.
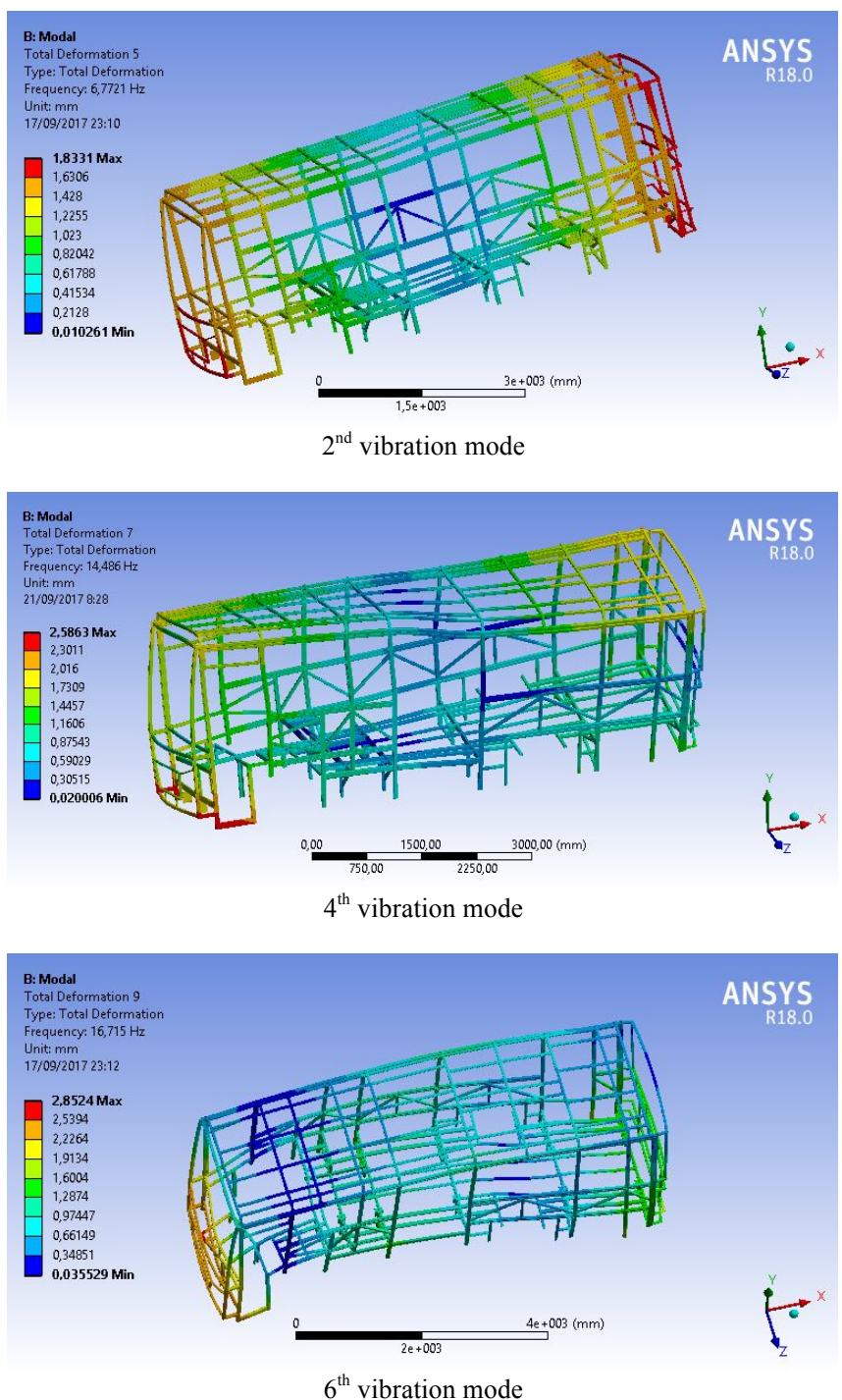

Figure 2 Vibration mode of bus body frame model 


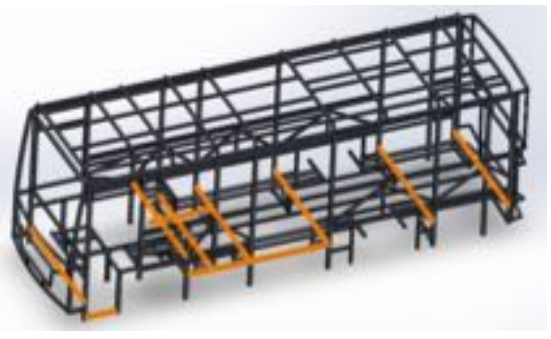

Beam_1 rectangular $80 \times 40 \mathrm{~mm}$

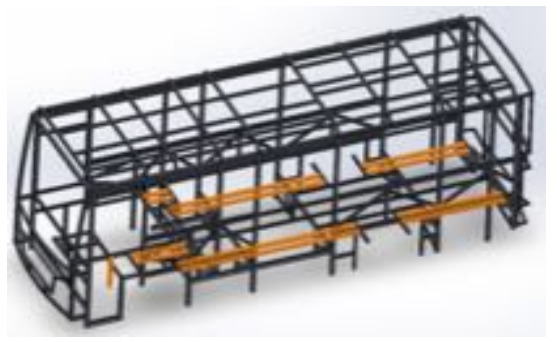

Beam_4 U-beam 60x40 mm

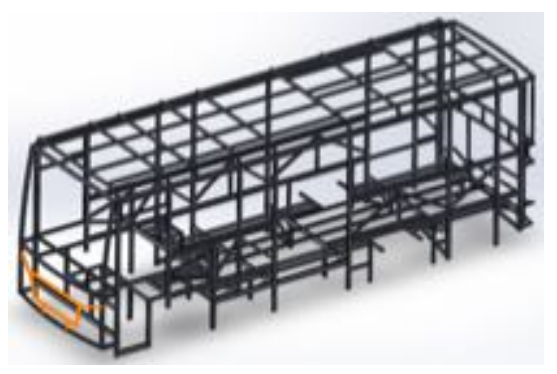

Beam_ 7 rectangular $40 \times 20 \mathrm{~mm}$

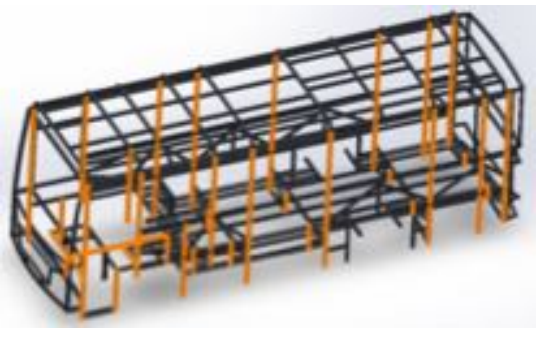

Beam 2 rectangular $60 \times 40 \mathrm{~mm}$

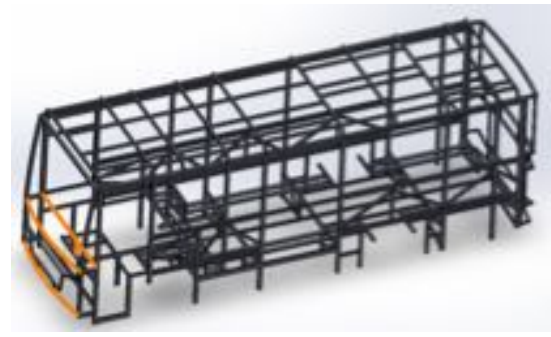

Beam_5 square 40x40 mm

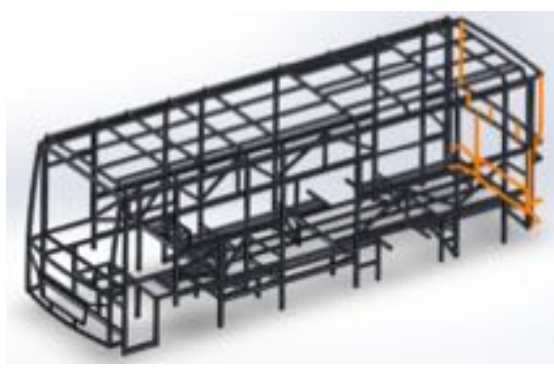

Beam_8 rectangular $40 \times 20 \mathrm{~mm}$

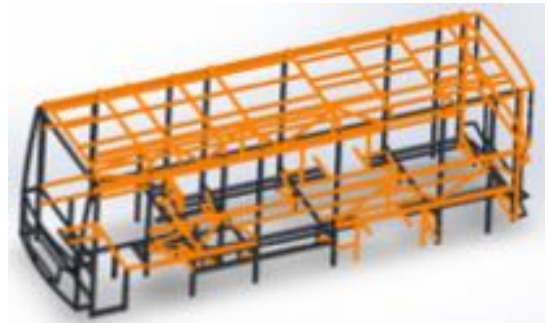

Beam 3 square $40 \times 40 \mathrm{~mm}$

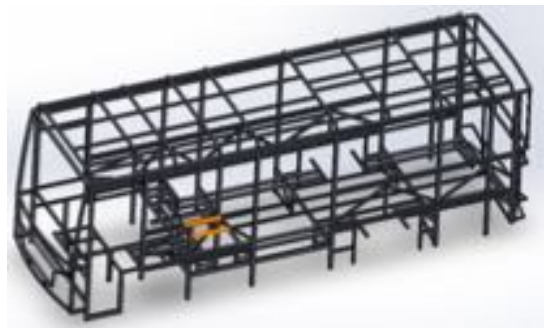

Beam_6 U-beam $60 \times 30 \mathrm{~mm}$

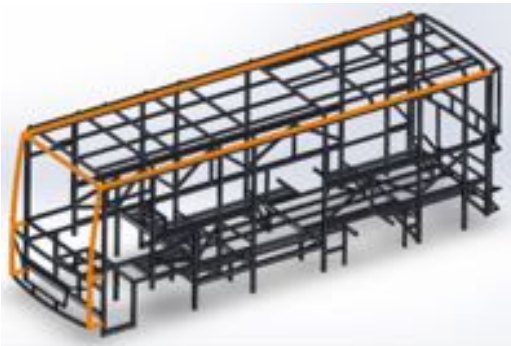

Beam 9 square $50 \times 50 \mathrm{~mm}$

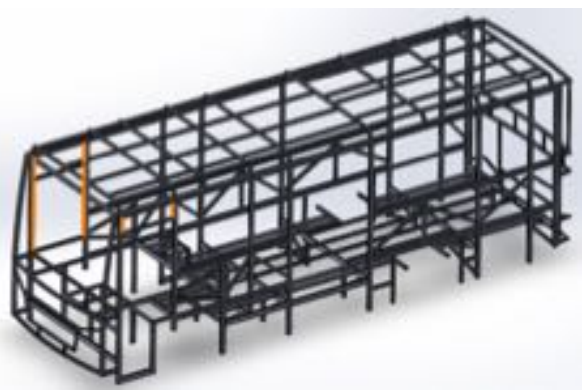

Beam $10 \mathrm{U}$-Beam 40x20 mm

Figure 3 Beam grouping of bus body frame

\section{Results}

In this study, the optimization was conducted using ASO to determine the minimum structural weight by means changing the thickness of tabular beam in each group as mentioned in the previous section. Table 4 shows the setting parameter used in present optimization. The convergence was satisfied by the number of evaluation of 329 , number of domain reduction of 4 and size of the generated sample set of 329 without any number of failures. Figures 4 and 5 show the history of structural mass and the natural frequency, respectively. Meanwhile, the comparison of the initial and optimum condition of the beam thickness of each group is given in Table 5 and the first six order natural frequencies of bus body frame are given in Table 6.

The results show that using ASO the structural weight of the bus frame can be reduced until $8.4 \%$ without any significant influence on the change of the first 6 order natural frequencies. This structural weight reduction is very important to the possibility of the bus design 
improvement to achieve the lower production costs and higher energy efficiency.

Table 4 Setting parameter of optimization

\begin{tabular}{cc}
\hline Parameter & Value \\
\hline Number of initial samples & 66 \\
Maximum number of evaluations & 500 \\
Convergence tolerance & 0.001 \\
Maximum number of candidates & 3 \\
\hline
\end{tabular}

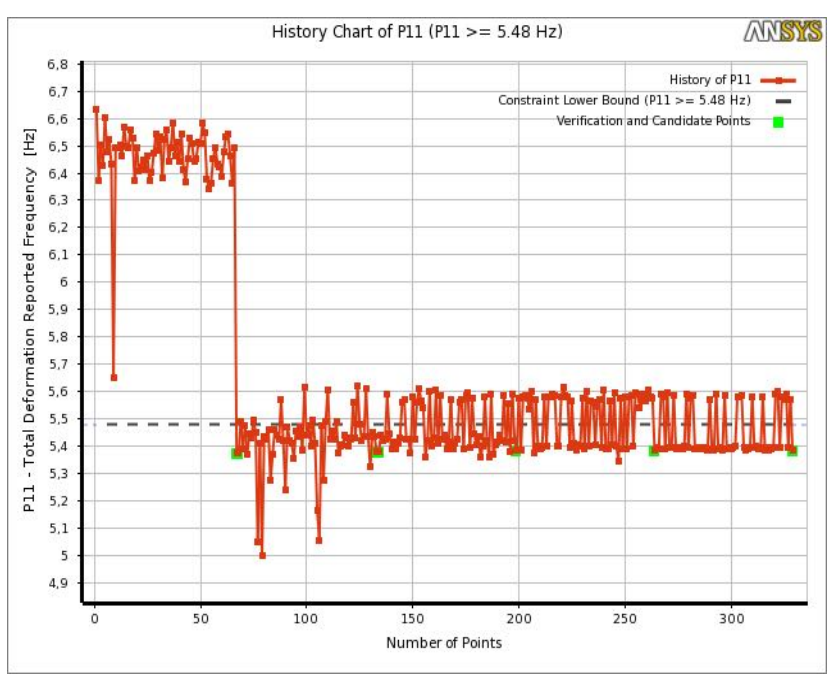

Figure 4 History of natural frequency of bus body frame

Table 5 Initial and optimum conditions

\begin{tabular}{cccc}
\hline \multirow{2}{*}{ Group of Beam } & \multicolumn{2}{c}{ Thickness (mm) } & Reduction \\
\cline { 2 - 3 } & Initial & Optimum & (\%) \\
\hline Beam_1 & 3.8 & 3.6 & -5.26 \\
Beam_2 & 2.3 & 2.1 & -8.70 \\
Beam_3 & 2.0 & 1.8 & -10.00 \\
Beam_4 & 2.3 & 2.1 & -8.70 \\
Beam_5 & 2.2 & 2.2 & 0.00 \\
Beam_6 & 2.3 & 2.5 & 8.70 \\
Beam_7 & 1.8 & 1.7 & -5.56 \\
Beam_8 & 1.75 & 1.7 & -2.86 \\
Beam_9 & 2.5 & 2.4 & -4.00 \\
Beam_10 & 1.8 & 1.7 & -5.56 \\
Structural Mass & $\mathbf{8 4 0 . 4 7}$ & $\mathbf{7 6 9 . 6 7}$ & $\mathbf{8 . 4 2}$ \\
\hline
\end{tabular}

Table 6 Natural frequency of initial and optimum conditions

\begin{tabular}{ccc}
\hline \multirow{2}{*}{ Order } & \multicolumn{2}{c}{ Natural Frequency (Hz) } \\
\cline { 2 - 3 } & Initial & Optimum \\
\hline $\mathbf{1}$ & 8,593 & 8,465 \\
$\mathbf{2}$ & 13,219 & 13,005 \\
$\mathbf{3}$ & 17,812 & 17,749 \\
$\mathbf{4}$ & 27,682 & 27,317 \\
$\mathbf{5}$ & 28,232 & 27,631 \\
$\mathbf{6}$ & 30,473 & 30,003 \\
\hline
\end{tabular}

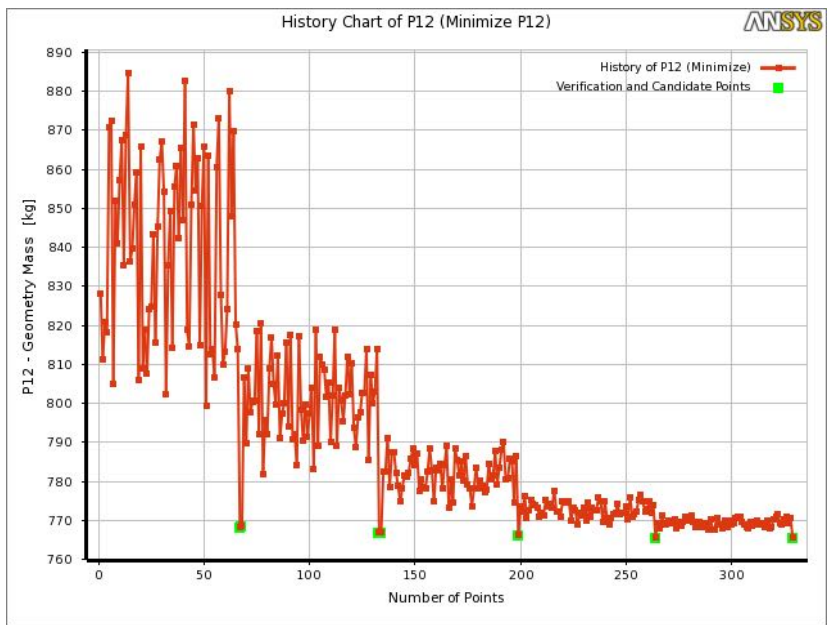

Figure 5 History of natural frequency of bus body frame

\section{Conclusion}

The optimization of the bus body frame was carried out using the size optimization with the thickness as variable and with the objective to minimize the structural mass. ASO method proved to be a useful tool in optimizing the tabular beams constructing bus body frame for reducing the structural mass without changing the dynamic characteristics.

\section{Acknowledgement}

This paper is supported by USAID through Sustainable Higher Education Research Alliances (SHERA) Program - Centre for Collaborative (CCR) National Center for Sustainable Transportation Technology (NCSTT) with grant no. IIE00000078-ITB-1.

\section{References}

[1] D. Margaritis, A. Anagnostopoulou, A. Tromaras, and M. Boile, "Electric commercial vehicles: Practical perspectives and future research directions," Research in Transportation Business \& Management, vol. 18, pp. 4-10, 2016.

[2] C. Link, U. Raich, G. Sammer, and J. Stark, "Modeling demand for electric cars - a methodical approach," Procedia - Social and Behavioral Science, vol. 48, pp. 1958-1970, 2012.

[3] F. Kley, C. Lerch, and D. Dallinger, "New business models for electric cars - a holistic approach," Energy Policy, vol. 39, pp. 3392-3403, 2011.

[4] G. Belingardi, "Lightweight design of vehicle body a contribution toward greener environment," Acta Technica Corvininesis - Bulletin of Engineering, vol. 7, pp. 165-169, 2014.

[5] W. Wanga, C. Zhoub, C. Linc, and J. Chen, "Electric bus body lightweight design based on multiple constrains," Advanced Materials Research, vols. 538-541, pp. 3137-3144, 2012.

[6] W. Zuo, J. Yu, and K. Saitou, "Stress sensitivity analysis and optimization of automobile body frame consisting of 
rectangular tubes," International Journal Automotive Technology, vol. 17, pp. 843-851, 2016.

[7] A. Gauchia, V. Diaz, M. J. L. Boada, and B. L. Boada, "Torsional stiffness and weight optimization of a real bus structure," International Journal Automotive Technology, vol. 11, pp. 41-47, 2010.
[8] R. K. Rathore, K. Sharma, and A. Sarda, "An adaptive approach for Single Objective Optimization," International Journal of Engineering Research and Applications, vol. 4, pp.737-746, 2014. 